\title{
Synthesis of 4-Aryl-5-arylidene-3-bromofuran-2(5H)-one Rubrolides Analogues
}

\author{
Barcelos $^{a}$, R. C.; Barbosa ${ }^{a \star}$, L. C. A.; Maltha ${ }^{a}$, C. R. A.; Demuner ${ }^{a}$, A. J.; Donà ${ }^{b}$, A.; \\ Forlani, G. ${ }^{\mathbf{b}}$ \\ ${ }^{a}$ Departamento de Química, UFV, Viçosa, Minas Gerais, Brasil \\ ${ }^{b}$ Department of Biology and Evolution, University of Ferrara, Ferrara, Italy \\ */cab@ufv.br
}

Keywords: $\gamma$-alkylidenebutenolides, rubrolides, phytotoxic activity.

\section{INTRODUCTION}

The $\gamma$ alkylidenebutenolides comprise a class of natural products presenting a variety of biological activities. Within this class of substances, there are the rubrolides (1a-d), lactones isolated from marine ascidians, which are recognized as a source of natural bioactive compounds. Rubrolides are known for their antibiotic, cytotoxic and anti-inflammatory activities. $^{1}$

Among the numerous phytotoxic products of microbial origin is cyanobacterin, a natural lactone isolated from the blue-green alga Scytonema hofmanni. Because of the high structural similarity between rubrolides and cyanobacterin, rubrolides 14a-k were synthetized and their ability to interfere with the photosynthetic electron transport chain in isolated spinach chloroplasts and in intact Chlorella cells were investigated.
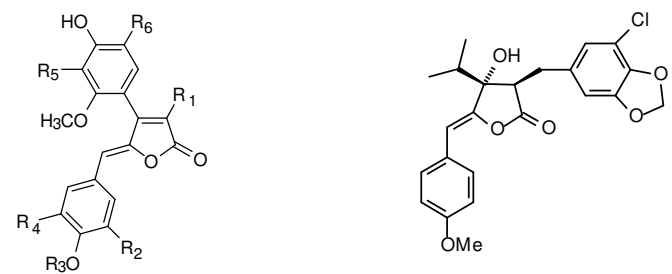

1a Rubrolide $A\left(R_{1}=R_{3}=H ; R_{2}=R_{4}=R_{5}=R_{6}=B r\right)$ 16 Rubrolide $B\left(R_{3}=H ; R_{2}=R_{4}=R_{5}=R_{6}=B r ; R_{1}=C l\right)$ 1c Rubrolide $C\left(R_{1}=R_{3}=R_{5}==R_{6} H ; R_{2}=R_{4}=B r\right)$ 1d Rubrolide $D\left(R_{1}=R_{2}=R_{3}=R_{4}=H ; R_{5}=R_{6}=B r\right)$

\section{RESULTS AND DISCUSSION}

The arylidenefuranones $\mathbf{1 4 a - k}$ were synthesized from mucobromic acid $\mathbf{2}$ as shown in Scheme 1. This compounds was reduced to 3,4-dibromofuran-2(5H)-one 3 in the presence of $\mathrm{NaBH}_{4}$ and methanol. After recrystallization, this brominated furanone was obtained as a white crystalline solid in $80 \%$ yield. Lactone 3 was then submitted to Suzuki coupling reactions with arylboronic acids $\mathbf{4}$ and $\mathbf{5}$, affording lactones 6 and 7 in $76 \%$ and $77 \%$ yield, respectively. Reaction of these furanones with various substituted aromatic aldehydes (8-13) in the presence of TBSOTf and DIPEA. The corresponding aldolic adducts formed were treated with DBU to produce the novel rubrolide analogues 14a-k. All compounds had their structures elucidates by spectroscopic analyses.

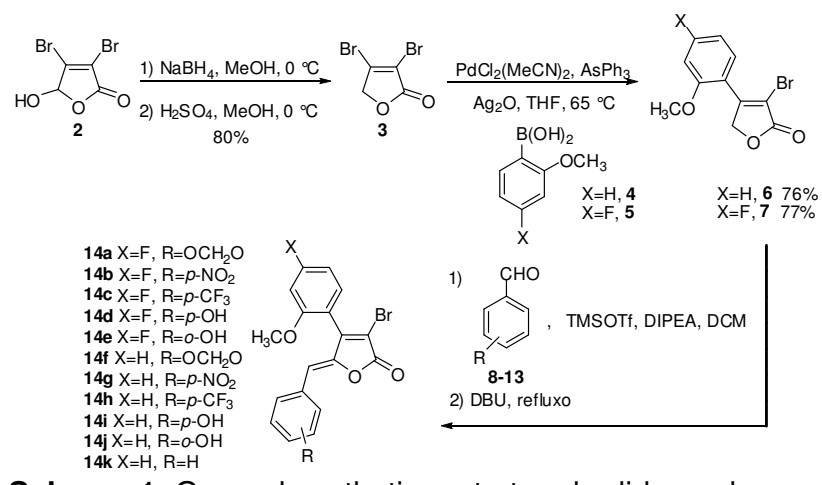

Scheme 1. General synthetic route to rubrolide analogues 14a-k.

The biological activities of all new compounds were evaluated in vitro as their ability to inhibit the photosynthetic electrons transport chain in spinach chloroplasts. The results have shown that some compounds were inactive and others were highly actives with the $I_{50}$ ranging from $1.1 \mu \mathrm{M}$ to $39 \mu \mathrm{M}$.

\section{CONCLUSION}

Eleven new lactones analogues of rubrolides were prepared from mucobromic acid in overall yields ranging from $21 \%$ to $46 \%$ over 3 steps. The ability of all compounds to inhibit the photosynthetic electron transport chain in chloroplasts was correlated with the nature of the substituents on the benzylidene ring. Further analogues need to be prepared and QSAR studies are required in orde to result in the development of highly phytotoxic compounds with potential use as herbicides.

\section{ACKNOWLEDGEMENTS}

FAPEMIG, CAPES and CNPq for financial support.

\section{REFERENCES}

${ }^{1}$ Pearce, A. N.; Chia, E. W.; Berridge, M. V.; Maas, E. W.; Page, M. J.; Webb, V. L.; Harper, J. L.; Copp, B. R. J. Natural Products. 2007, 70, 111.

${ }^{2}$ Teixeira, R. R.; Barbosa, L. C.; Forlani, G.; Piló-Veloso, D.; Carneiro, J. W. M. J. Agric. Food Chem. 2008, 56, 2321. 